\title{
Controlling a demographic wave in defined contribution pension systems
}

\author{
MASSIMO ANGRISANI* \\ Department MEMOTEF \\ Sapienza University of Rome \\ 00161 Rome, Italy \\ and \\ CinZIA DI PALO ${ }^{\dagger}$ \\ Department of Economics and Law \\ University of Cassino and Southern Lazio \\ 03043 Cassino (FR), Italy
}

(Received: April 29, 2015)

\begin{abstract}
In several developed countries, the baby boomers will come to retire in the next decades. This problem will threaten the sustainability and the intergenerational equity of mandatory pay-as-you-go pension systems because they will have to drain the "demographic wave" of retirees with a relatively small number of contributors. In this paper, we give the operating method developed on the basis of a general principle, which a defined contribution pension system, in a state of stable sustainability, should adopt to control these issues in the presence of a demographic wave. In the theoretical profile, our approach breaks and overcomes the classical juxtaposition between funded and pay-as-you-go pension schemes, carrying out the integration of the two financial methods.
\end{abstract}

Mathematics Subject Classifications (2015). $91 \mathrm{~B} 15$

Keywords. Mandatory pension system control; baby boom demographic wave; logical sustainability; intergenerational equity.

\section{Introduction}

The forthcoming retirement of baby boomers is a well-known problem, which is going to put severe pressure on sustainability and intergenerational equity of existing pay-as-you-go (PAYG) pension systems of several developed countries (see, e.g., among many others, [6], [11). Italy is an excellent example in this regard, as the baby boom generations of the post-Second World War are going to

*e-mail: massimo.angrisani@uniroma1.it

†e-mail: c.dipalo@unicas.it 
retire in the next 2030s. However, other European countries, such as Germany, France, Spain, or Poland, need to face the same problem, as clearly highlighted by the shape of their population pyramids. In the last decades, many countries have implemented reform processes, but these reforms substantially aimed at containing the pension expenditure by means of measures such as the increase in the retirement age or in the contribution rate, as well as the reduction of pension benefits. Aiming at sustainability together with the intergenerational equity, some countries, amongst which Italy and Sweden, implemented Notional Defined Contribution (NDC) pension schemes. For a comprehensive review of the recent experiences of countries where NDC have been implemented, see [8], [9].

In the literature, the problem of the interactions between the sustainability of PAYG pension systems and disturbances produced by a demographic wave has been studied in the last decades, see, e.g., [5], [12. However, to our knowledge, there exists no operating method able to control the relevant phenomenon of a demographic wave so that a pension system, in a state of stable sustainability, remains sustainable and substantially preserves fairness at the same time. This is the objective of our paper. Specifically, we provide the operating method, based on a general principle, for controlling the demographic wave in the framework of the logical sustainability, introduced in [1, 2] in relation to defined contribution (DC) pension systems with a funded component, and developed in [4 in relation to these systems in a state of stabilisation. Our main result consists in proving that in order to face the demographic wave problem it is not possible to exclusively follow a PAYG scheme, as well as it is not necessary to shift to a fully-funded scheme, despite of the belief of some authoritative authors, see e.g. [7, [13]. In the theoretical profile, the approach we propose breaks and overcomes the classic juxtaposition between funded and PAYG pension schemes and carries out the integration of the two financial methods by means of an appropriate procedure, which involves also the rate of return on the pension liability. It should be highlighted that the procedure we introduce is linked entirely to the actual trend of the pension system variables (like assets and liabilities), and it is not based on actuarial projections. Such an approach is not unusual in the actuarial practice. We recall that one of the innovative aspects of the well-known Swedish pension system is in the idea that the assets and the liabilities are to be calculated "... on the basis of events and transactions that have occurred and been recorded, thus without projections ...", see [15], p.10. Furthermore, in the current work we neglect problems such as longevity and/or price stochasticity that, although relevant, involve technicalities but do not prejudice to the basic principle underlying our study, whereby it is necessary funding everything, and only this, that is PAYG unmanageable, i.e. the demographic wave.

This paper is structured as follows. Firstly, we briefly recall the basics of the logical sustainability model. Secondly, we deal with the demographic wave problem and introduce the basic concepts of our approach. Successively, the operating method is formally explicated by means of a separation theorem, which is proved under the assumption that the rate of return on the fund is not 
less than the wage growth rate. Numerical illustration of the proven separation theorem is also provided by means of a consistent actuarial model.

\section{The basics of the logical sustainability model}

In this section, from [2], we recall some basic features of the logical sustainability model, which has to be considered the theoretical framework of our study. The logical sustainability model considers a DC pension system provided with a funded component. In order to simplicity, but without loss of generalisation, the rule for the benefit calculation does not take into account disability pensions and survivor benefits. Pension benefits are calculated by dividing the total pension credit by the annuity divisor at the time of retirement. The annuity divisor is based on the actuarial equilibrium between contributions and pensions and, hence, it depends on life tables. The annuity divisor depends also on the technical rate, namely a pre-paid rate of interest, which is chosen equal to zero. Hence, since the pension system does not pay out for survivor benefits, the annuity divisor coincides with the remaining life expectancy at the time of retirement. Pensions are revalued by the rate of return on the pension liability. This rate is net of the "implicit demographic rate", which depends on both the demographic structure of the retirees group and the biological parameters, see the definition in [2, p. 70 .

We assume throughout the paper that the time interval is $T=\left[t_{*}, t_{f}\right]$, where $t_{f}$ could also be equal to $+\infty$. All functions are defined in $T$ and have the necessary regularity for all next formalisations. The instantaneous flow functions are evaluated on a yearly basis.

For each $t$ in $T$, we consider the following functions:

$\alpha(t)$ is the contribution rate, with $\alpha(t) \geq 0$;

$C(t)$ and $W(t)$ are the instantaneous flows of contributions and wages, respectively, with $C(t) \geq 0, W(t)>0$, and $C(t)=\alpha(t) W(t)$;

$P(t)$ is the instantaneous flow of pension expenditure at time $t$, with $P(t)>0$; $L^{A}(t)$ is the pension liability to contributors (defined as the latent pension liability), with $L^{A}(t) \geq 0$;

$L^{P}(t)$ is the pension liability to retirees (defined as the current pension liability), with $L^{P}(t)>0$;

${ }^{A} L^{P}(t)$ is the instantaneous flow of the latent pension liability, which at time $t$ is transformed into the current pension liability;

$L^{T}(t)$ is the total pension liability, with $L^{T}(t)>0$ and $L^{T}(t)=L^{A}(t)+L^{P}(t)$; $F(t)$ is the pension system fund;

$r(t)$ is the instantaneous rate of return on the fund;

$r_{L}^{A}(t)$ is the instantaneous rate of return on the pension liability to contributors;

$r_{L}^{P}(t)$ is the instantaneous rate of return on the pension liability to retirees.

In the following, we assume that the rates of return on the latent and the current pension liability are equal, namely

$$
r_{L}^{A}(t)=r_{L}^{P}(t)=r_{L}(t)
$$


where $r_{L}(t)$ is the instantaneous rate of return on the total pension liability. We have to consider that retirees' benefits earn the implicit return deriving from the progressive extension of life expectancy, whose effects are measured by the implicit demographic rate. The rate of return on the current pension liability implicitly encompasses this effect; therefore, the rate of interest to return explicitly to the retiree pension liability should be equal to the difference between rate $r_{L}(t)$ and the implicit demographic rate. Furthermore, it should be noted that rate $r(t)$ can be linked to bonds issued in connection with the contributions collected by the pension system.

Definition 1 A pension system is sustainable in time interval $T$ if and only if $F(t) \geq 0$ for each $t$ in $T$.

Function $F(t)$ is connected to contributions $C(t)$ and pension expenditure $P(t)$ by the basic differential equation

$$
\dot{F}(t)=F(t) r(t)+\alpha(t) W(t)-P(t) .
$$

The change in the pension system assets is equal to the return on the fund plus the difference between contributions and pension expenditure.

Furthermore, a basic evolution equation is obtained for the total pension liability. We start with considering the differential equations describing the evolution of pension liability for the active and retiree population, respectively

$$
\begin{gathered}
\dot{L}^{A}(t)=L^{A}(t) r_{L}(t)+\alpha(t) W(t)-{ }^{A} L^{P}(t) \\
\dot{L}^{P}(t)=L^{P}(t) r_{L}(t)+{ }^{A} L^{P}(t)-P(t) .
\end{gathered}
$$

It should be noticed that the retiree pension liability, whose evolution is expressed by (3), is the probabilistic component of the pension liability because its evaluation is based on life tables. From (2) and (3), the differential equation of evolution of the total pension system is derived

$$
\dot{L}(t)=L(t) r_{L}(t)+\alpha(t) W(t)-P(t) .
$$

Equation (4) provides the evolution of the total pension liability for a DC pension scheme based on the actuarial equilibrium between contributions and pensions. We have to highlight that in (4) the following assumptions are made: a) the whole contribution amount transforms into pension liability, including too, for example, the contributions of those who died during their working life; b) the technical rate is equal to zero; c) the life tables are constant, hence the implicit demographic rate is equal to zero; d) the rates of return on the pension liability for both contributors and pensioners are equal.

DeFinition 2 For each instant $t$ in time interval $T$, the unfunded pension liability is $L^{U N}(t)=L^{T}(t)-F(t)$. 
It is assumed that $L^{T}(t) \geq F(t)$, and consequently that $L^{U N}(t) \geq 0$, for each $t$ in $T$.

Taking into account equations (1) and (4), we obtain the differential evolution equation for the unfunded pension liability. It is

$\dot{L}^{U N}(t)=L^{T}(t) r_{L}(t)-F(t) r(t)$.

Furthermore, we consider the following indicators.

Function $D_{c}(t)$ is the degree of funding of the pension liability; for each $t$ in $T$, it is defined as $D_{c}(t)=\frac{F(t)}{L^{T}(t)}$, with condition $0 \leq D_{c}(t) \leq 1$. It also results $1-D_{c}(t)=\frac{L^{U N}(t)}{L^{T}(t)}$, for each $t$ in $T$.

Function $\nu(t)$ is the divisor of the total pension liability in the current pension liability; for each $t$ in $T$, it is defined as $\nu(t)=\frac{L^{T}(t)}{L^{P}(t)}$, with $\nu(t) \geq 1$.

Function $\gamma(t)$ is the divisor of the current pension liability in the pension expenditure; for each $t$ in $T$, it is defined as $\gamma(t)=\frac{L^{P}(t)}{P(t)}$.

Function $\gamma(t) \nu(t)$ is the divisor of the total pension liability in the pension expenditure; for each $t$ in $T$, it is defined as $\gamma(t) \nu(t)=\frac{L^{T}(t)}{P(t)}$.

Function $\beta(t)$ is the level of the unfunded pension liability in relation to wages; for each $t$ in $T$, it is defined as

$$
\beta(t)=\frac{L^{U N}(t)}{W(t)} .
$$

Finally, we recall an efficient rule on the rate of return that has to be recognised on the pension liability in order to obtain the stabilisation of the unfunded pension liability in relation to wages.

Proposition 1 (Rule For the Stabilisation of indicAtor $\beta(t)$ ) It is assumed that $0 \leq F\left(t_{*}\right)<L^{T}\left(t_{*}\right)$. For each $t$ in $T$, it results $\dot{\beta}(t)=0$, and hence $\beta(t)=\beta\left(t_{*}\right)$, if and only if

$$
r_{L}(t)=r(t) \frac{F(t)}{L^{T}(t)}+\frac{\dot{W}(t)}{W(t)} \frac{L^{T}(t)-F(t)}{L^{T}(t)} .
$$

Under assumption of a sustainable pension system, this rule allows to control the expansion of the unfunded pension liability in relation to wages if and only if the rate of return recognised on the pension liability is equal to the weighted average of the rate of return on the fund, $r(t)$, and the relative instantaneous wage growth rate, given by $\frac{\dot{W}(t)}{W(t)}$.

\section{Generalities to control the demographic wave}

In this section, we aim at introducing the operating method that a DC pension system, which is in a state of stable sustainability, see [4, should adopt to control issues of sustainability and intergenerational equity in the presence of a "demographic wave". 
The approach we propose considers a DC pension system in a state of stable sustainability. This means that, in keeping with [4, we assume that the pension system:

- is DC type with a funded component and with a constant contribution rate;

- applies the $\beta(t)$ indicator stabilisation rule;

- is in a state of general stability, namely the divisor of total pension liability in pension expenditure, $\gamma(t) \nu(t)$, is stable around a constant value.

Furthermore, the pension system experiences a constant number of new entrants with stable wage profiles.

The demographic wave disrupts the condition of general stability of the pension system. To represent this phenomenon, we assume that an extra-number of new active individuals, over and above the stability value, enters the pension system for a limited time interval. These individuals may also have income profiles that are neither stable nor consistent with those of the individuals of the pre-existing stable part of the system. For example, they could be young people with a no stable working life or immigrants who temporarily participate in the system. A variety of studies examines the effects that the immigration might have relatively to the sustainability of a PAYG pension system by means of appropriate policies. For example, on the issue of the determination of an optimal immigration strategy, which steers the population towards a demographic equilibrium, see [3], 14]. In any case, in order to our model, we assume that the wage dynamics of the stable part of the pension system are not modified by the demographic wave.

Since we aim exclusively at considering the effects of the demographic wave, we assume constant survival rates and, hence, we abstract from issues deriving from improvements in longevity. Furthermore, we assume that there is a maximum attainable age and that this assumption is consistent with the regularity hypotheses of the functions involved.

Our approach aims at preserving the stability over time of the pre-existing part of the pension system even if disruptive phenomena of demographic disequilibrium entered the pension system. This means that all that causes disequilibrium, hence active people who outnumber the stability value of the new entrants, should be placed in a separate part of the pension system, which will be financially managed according to the fully-funded scheme.

The two parts of the pension system, both the pre-existing stable part and the part linked to the demographic wave, have to be equivalent under the pension profile. Namely, they have to share the same rules and, in particular, the same rate of return on the pension liability whereby it is indifferent for an individual whether he/she joins the first or the second subsystem.

We deeply describe our approach and explain the relative technicalities.

Let $T$ be the time interval considered and let $t_{i}$ belong to $T$. Starting from $t_{i}$, the number of new entrants gradually increases in relation to the stability value and successively decreases until it reaches the stability value again. 
Starting from $t_{i}$, we place the new entrants in two subsystems, which are separated in relation to the number of individuals accepted but are integrated in relation to the financial management. However, they belong to a unique total system.

The first subsystem constitutes the natural prosecution of the already existing stable pension system. Therefore, it continues to receive the same number of new entrants with regular salary dynamics and it remains in a state of economic, financial, and demographic stability. We refer to this as the Pivot Pension System.

Differently, the second subsystem receives the individuals who numerically exceed the stability value of the new entrants and may have unstable salaries or unstable salary dynamics. It has to follow the fully-funded scheme. We refer to this as the Auxiliary Pension System. When the total number of new entrants goes back to the stability value, the Auxiliary Pension System does not receive new participants and becomes a closed group, which exhausts when the last participant dies.

All individuals joined the pension system, indifferently belonging to the Pivot Pension System or the Auxiliary Pension System, pay contributions according to a fixed contribution rate, share the same rules for the pension calculation, and enjoy the same return on the pension credit.

In the next section, we set up our approach by means of a theorem, which provides the control procedure to be used so that a stable pension could preserve its sustainability without changing the contribution rate, the pension level or the retirement age, with substantial respect to the intergenerational equity.

\section{The separation theorem to control the demo- graphic wave}

In this section, we formalise the separation theorem that explicates the financial strategy and the rule on the rate of return on the pension liability in order to control the disruptive effects of the demographic wave. In the following, maintaining the denominations of the previously introduced functions, we use the following notations.

During the wave phase, we need to refer to functions, both variables and indicators, of three different systems: the Pivot, the Auxiliary, and the Total Pension System, given by the union of the two previous ones. Hence, we use "1" and "2" in subscript to refer to the functions of the Pivot and the Auxiliary Pension System, respectively. We do not use any subscript to refer to the functions of the Total Pension System. Summing up, we are going to consider the Pivot Pension System $\left(P P S_{1}\right)$, the Auxiliary Pension System $\left(A P S_{2}\right)$, and the Total Pension System (TPS ).

Furthermore, the proof of the separation theorem is conducted by comparing $P P S_{1}$ with the pre-existing stable pension system that would have resulted from a constant number of new entrants with unaltered wage profiles and which has 
not experienced the demographic wave. Obviously, starting from $t_{i}$, this system is a virtual stable system, to which we refer as the Stable Pension System. Since it receives the same individuals of $P P S_{1}$, we use the subscript "1" to refer to its functions but we denote all its functions with the superscript "-", since their values do not change for demographic wave effect. Hence, this system is indicated as $\overline{S P S}_{1}$ throughout the paper. It should be noticed that the instantaneous flows of wages and contributions are equal for both systems, $\overline{S P S}_{1}$ and $P P S_{1}$, as they receive the same constant number of individuals with the same stable wage profiles and we have assumed that the individuals of the demographic wave do not change the productivity of the stable part of the pension system.

Theorem 1 (The Separation theorem) The DC Pension System is in a state of a stable sustainability: it has a constant contribution rate; it recognises the rate of return on the pension liability according to (6); and there is a constant ratio between pension liability and pension expenditure.

Let $t_{i}$ be the time in $T$ starting from which the demographic wave enters into the Pension System. Starting from $t_{i}$, the Total Pension System is separated in the two subsystems, $P P S_{1}$ and $A P S_{2}$, each one with the same constant contribution rate. Furthermore, it is assumed that:

[A1] the instantaneous rate of return on the funds and the instantaneous growth rate of wages are both constant, $r$ and $\bar{\sigma}_{1}$ respectively, and such that $r \geq \bar{\sigma}_{1}$;

[A2] the two subsystems recognise the same instantaneous rate of return on the pension liability, namely $r_{L 1}(t)=r_{L 2}(t)$, and both are equal to $r_{L}(t)$ that follows the rule

$$
r_{L}(t)=r D_{c}(t)+\bar{\sigma}_{1}\left(1-D_{c}(t)\right)
$$

[A3] the instantaneous flow $F_{2}(t)\left(r-r_{L}(t)\right)$, named compensation flow, is transferred from $A P S_{2}$ to $P P S_{1}$.

Then for each $t \geq t_{i}$, we have:

[T1] $A P S_{2}$ is fully-funded;

[T2] $\dot{\beta}_{1}(t)=0$, and hence $\beta_{1}(t)=\bar{\beta}_{1}$ with $\bar{\beta}_{1}=\bar{\beta}_{1}\left(t_{i}\right)$;

[T3] $P P S_{1}$ is sustainable.

See Appendix A for the proof.

REMARK 1 It is not hard to see that the control procedure in the theorem remains valid if the rate of return on the fund is not constant but it is not less than the growth rate of wages. 


\section{Numerical exemplification of the demographic wave control}

In this section, we implement a consistent actuarial model to illustrate the control procedure described in the separation theorem. Following [4, we consider a discrete time model of the pension system instead of a continuous time model as in our theory. We neglect issues stemming from the adjustment between the two models, because they are not relevant to our conclusions under the substantial profile.

We consider a DC pension system starting from its initial phase, namely starting from the year (time unit) of the first entries in the pension system. The following assumptions are made:

- the time interval is $[0, \infty)$ : we analyse the first 300 years;

- the number of new entrants (in our example, only male gender) in the pension system is constant over time and is equal to 1000 units per year; this number is the stability value of new entrants;

- each new member joins the scheme at age 25 and works until age 65;

- at age 65 , the member retires and receives a pension until he is alive. A maximum age exists and is denoted by $\omega$. No survivor pension is considered;

- mortality rates are constant over time. Their values are those of the Life Table for Italy, Males, Last Modified March 2011, year 2008, downloaded from [10]. According to this Life Table, $\omega$ is equal to 110;

- the "wage step", namely the ratio, reduced by one, of the average wage at age $x$ to the average wage at age $(x-1)$ is constant and equal to 2 percent. The growth rate of productivity, $g$, which is used to increase the average wage for each age group $x$ for each year, is constant in relation to age and time. Therefore, the wage-pattern is stable over time;

- the contribution amounts paid in by workers who die during their active lives are redistributed to survivors of the same age group;

- the individual pension is calculated by dividing the total individual pension credit by the annuity divisor at the retirement age of 65 (in the annuity divisor the technical rate is set at zero, hence, the annuity divisor coincides with life expectancy at the retirement age). As with the assumption on constant mortality rates, the annuity divisor at retirement age remains unchanged over time. Pensions are paid at the end of the year and are revalued each year according to the rate of return on pension liability;

- rate $r_{L}$ is equally returned to the pension liability for both workers and pensioners; 


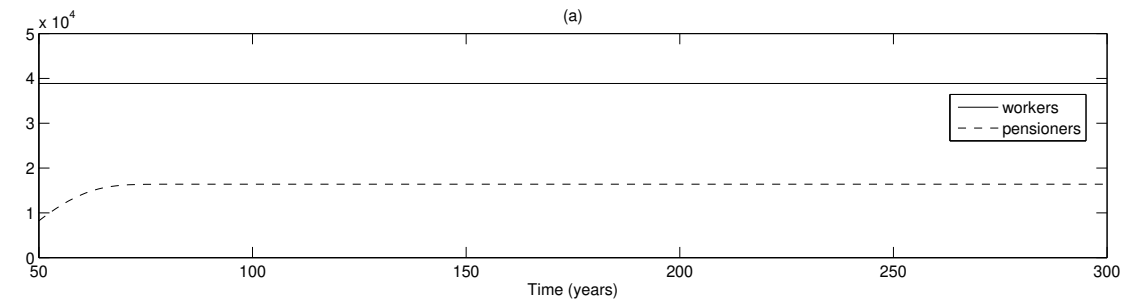

(b)

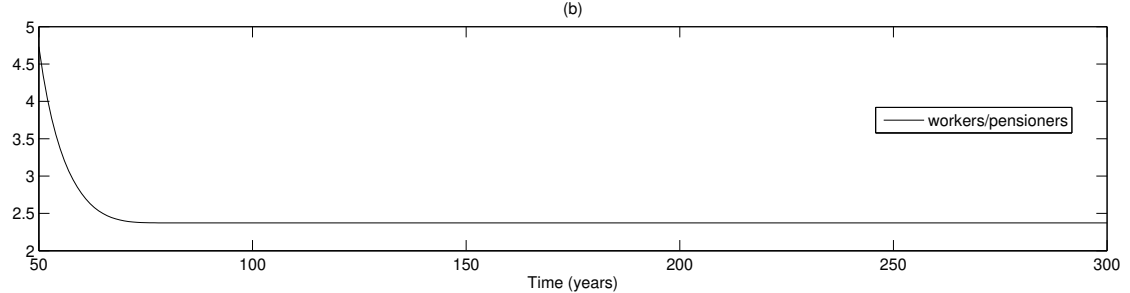

Figure 1: During the demographic wave phase, (a) number of workers and pensioners and (b) ratio of workers to pensioners. Source: Authors calculation.

- the fund is revalued each year according to rate of return $r$, which is assumed to be constant over time.

Under the above-specified assumptions, we have the general stabilisation of the pension system. As a specific consequence of the assumptions on a constant number of entries, a constant age of entry and retirement, and constant mortality rates, it follows that the number of workers becomes stationary after forty years and the number of pensioners becomes stationary after a life cycle (78 years) of the pension system, see Figure 1(a). Hence, the worker-to-pensioners ratio is also stationary and it is equal to 2.373, see Figure 1(b). After the first forty years, the wage growth rate coincides with the growth rate of productivity.

Starting from the initial time, we assume $\alpha=16 \%, r=3 \%, g=2 \%$, $r_{L}=4 \%$.

In this case, the pension system recognises too high a rate of return on the pension liability and this determines a progressive reduction of the fund until it falls under zero, see the examples in [4]. In order to the sustainability, the pension system has to recognise the rate of return on the pension liability according to the $\beta(t)$ indicator stabilisation rule when the degree of funding of the pension liability falls under a fixed value. In our simulation, we intervene at $t_{*}=90$ when the degree of funding of the pension liability falls below the $32 \%$ level.

Applying the stabilisation rule, $\beta(t)$ remains constant and equal to $\beta\left(t_{*}\right)$, that is 4.468 . Furthermore, the pension system remains sustainable in $T$, as we can verify looking at the trend of the degree of funding of the pension liability, which is positive for each $t$ in $T$ and stabilises at a value of $1.987 \%$, see Figure 


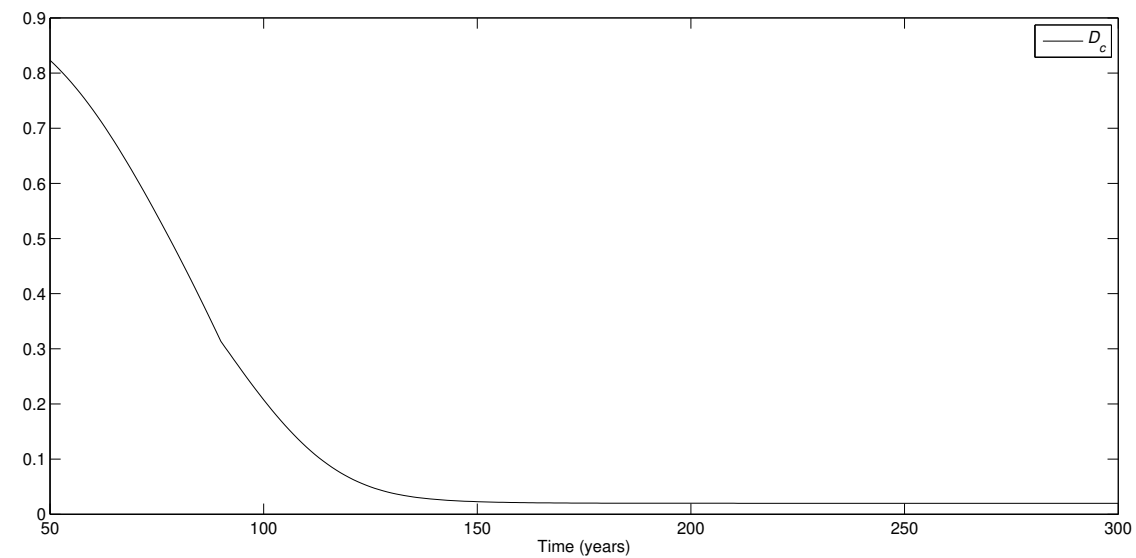

Figure 2: Trend of the degree of funding of the pension liability. Source: Authors calculation.

2

In this manner, under the above-specified assumptions of economic and demographic stabilisation and by means of the application of the $\beta(t)$ indicator stabilisation rule, the pension system remains sustainable over time without adjusting the contribution rate and with a low degree of funding.

In this situation of stability and sustainability over time, we assume that starting from $t_{i}$ the pension system has to face the demographic wave problem. In order to simulate the flow into the pension system of the demographic wave, we assume that the number of new entrants by year is greater than the stability value starting from $t_{i}$ and for a fixed time interval. Specifically, the following assumptions are made.

- At time $t_{i}=180$, the number of new entrants begins to increase in relation to the stability value.

- The number of new entrants has a constant yearly increase, equal to 200 units per year, for the first five years, from the $180^{t h}$ to the $184^{t h}$ year. Then it remains constant over the subsequent ten years, from the $185^{\text {th }}$ to $194^{\text {th }}$ year; hence, it decreases yearly by a constant number, equal to 200 units per year, for another five years, from the $195^{t h}$ to the $199^{t h}$ year. The number of new entrants goes back to the stability value that is 1000 units per year starting from year 200 .

As results of the upheaval of the demographic wave, the state of demographic stability of the pension system is broken. The number of both workers and pensioners are no longer stationary and, therefore, the worker-to-pensioner ratio fluctuates compared to the stability value. We have the situation illustrated in Figure 3 

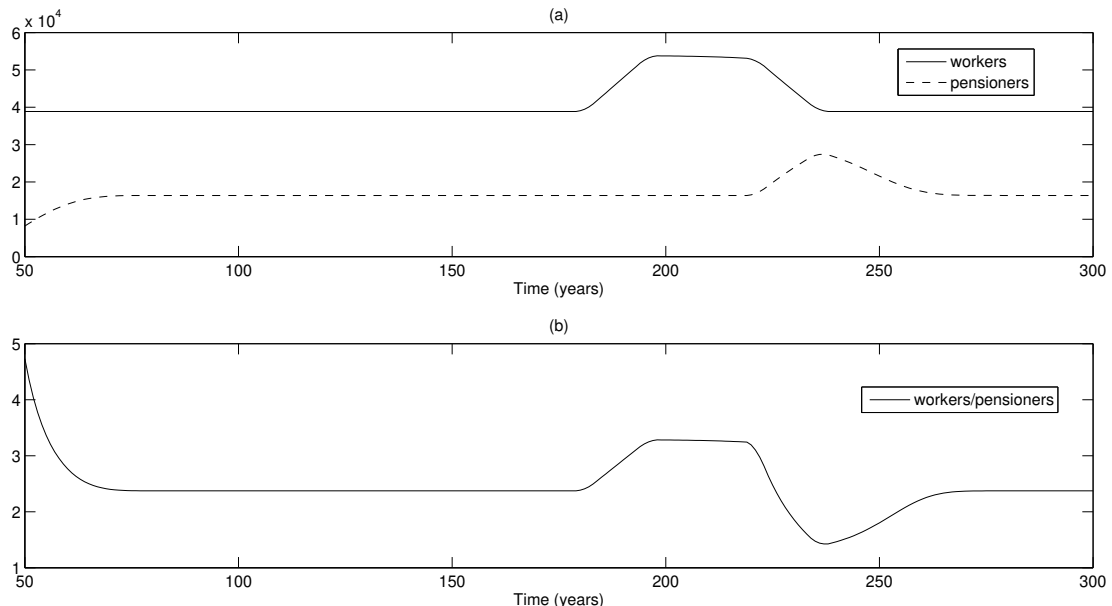

Figure 3: During the democratic wave phase, (a) number of workers and pensioners (b) ratio of workers to pensioners. Source: Authors calculation.

In order to achieve the pension system sustainability, starting from $t_{i}=180$, we apply the separation theorem. Hence, we consider the participants belonging to the two subsystems, $P P S_{1}$ and $A P S_{2}$, and we recognise the rate of return on the pension liability according to (7). Furthermore, we note that a compensation transfer is always possible from $A P S_{2}$ to $P P S_{1}$, since it is $r \geq \bar{\sigma}_{1}$ under the economic assumptions used in our example. Being that all assumptions of the separation theorem are satisfied, we verify that:

- $\beta_{1}(t)$ is constant for each $t \geq t_{i}$ and it is equal to $\beta_{1}\left(t_{i}\right)=4.468$, see Figure 4

- the fund of the Total Pension System, which is equal to the sum of the two subsystems funds, is greater than 0 , hence the pension system is sustainable, see Figure 5

The pension system sustainability is obtained by means of the application of the separation theorem without increasing the contribution rate. Furthermore, we note that the application of rule (7) of the separation theorem permits and maintains the intergenerational equity in spite of the significant oscillation in the worker-to-pensioner ratio. In this regard, we can look at Figure 6, where we note that the average pension-to-average wage ratio remains nearly closed to the stability value, which is about 0.38 (the oscillation range of this ratio is $0.3745-0.4133$, while the oscillation range of the worker-to-pensioner ratio is $1.424-3.283$, stability value 2.373$)$. 


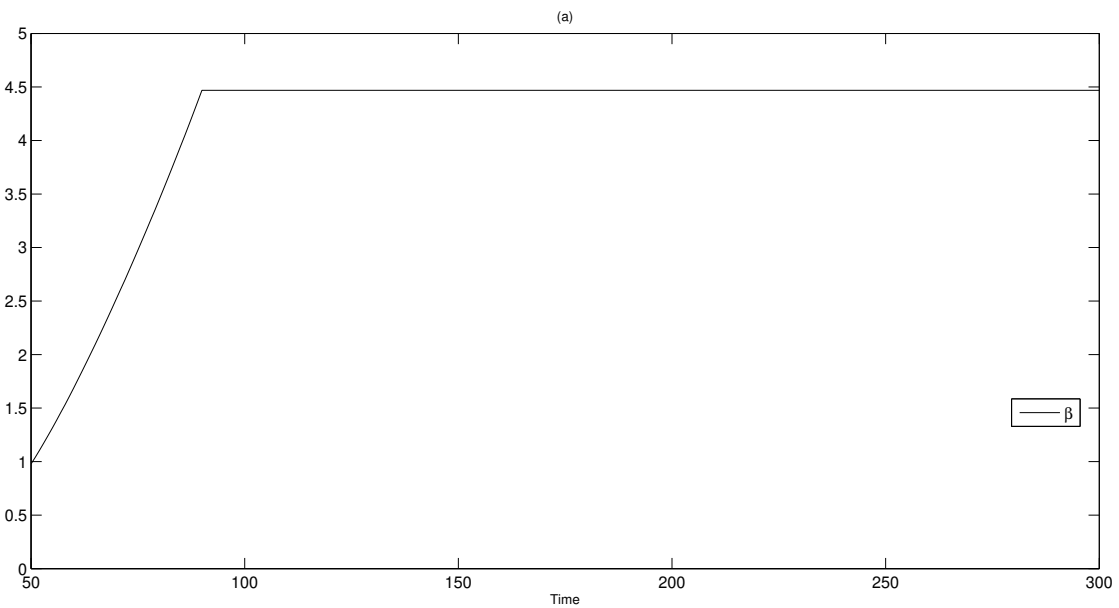

Figure 4: Trend of the level of the unfunded pension liability in relation to wages for the Pivot Pension System. Source: Authors calculation.

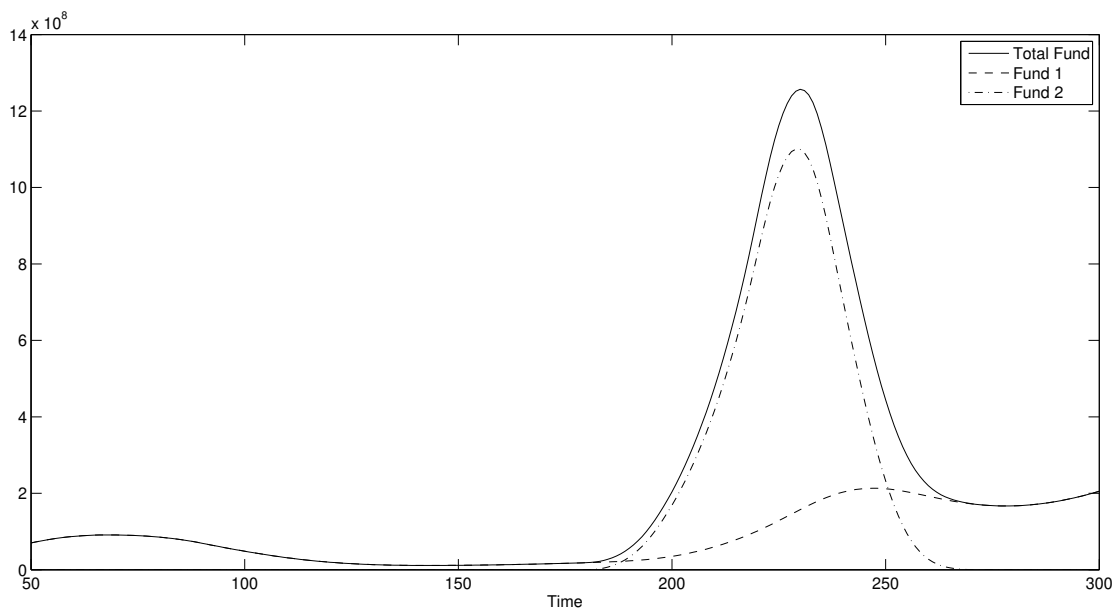

Figure 5: Trend of the funds when we apply the separation theorem. Source: Authors calculation. 

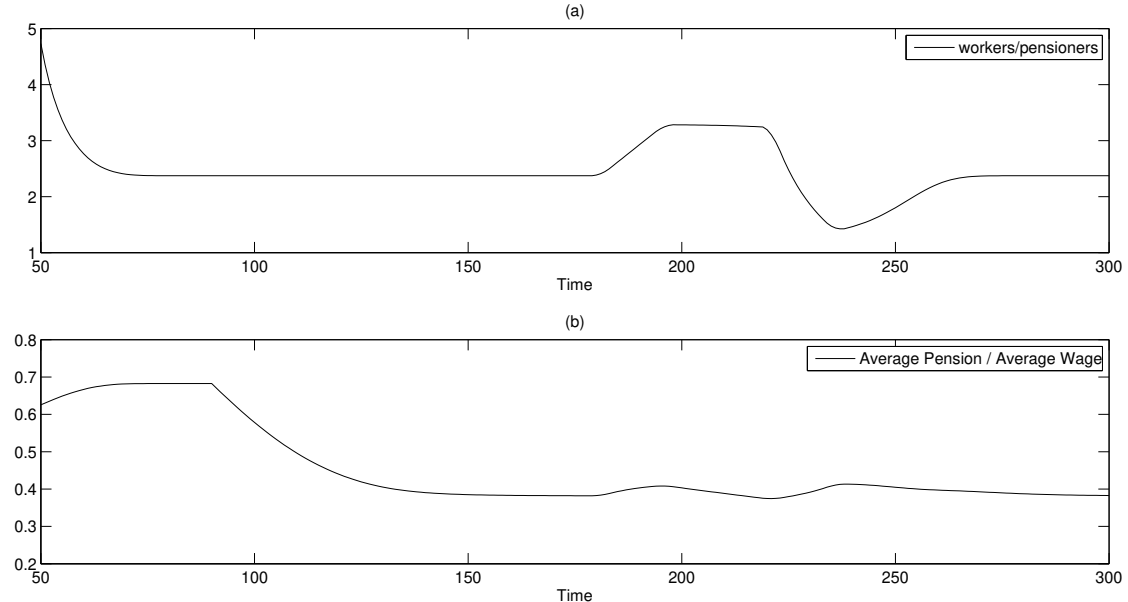

Figure 6: (a) Worker-to-pensioner ratio (b) Average-pension-to-average-wage ratio.Source: Authors calculation.

\section{Conclusions}

The present study has focused on issues of sustainability and intergenerational equity that a stable DC pension system has to face when a demographic wave disrupts the equilibrium. In the framework of the logical sustainability, see [1], and [2], the main contribution of this work consists in providing an operating procedure to control these issues in an efficient manner. We proved that it is not possible to exclusively follow the PAYG scheme but, at the same time, the procedure proposed does not involve the very burdensome shift of the pension system to the fully-funded scheme, as is suggested, e.g., in [7], [13].

Our procedure relies on a basic theorem of separation that assumes a constant contribution rate, the rule for the stabilisation of the level of the unfunded pension liability in relation to wages, and the stable sustainability of the system. Our results are obtained assuming the classical hypothesis that the rate of return on the fund is not less than the wage growth rate. Further developments of this study are going to provide a unified theorem under more general hypotheses on the dynamics of interest rates and life tables.

\section{A Appendix}

Proof of the separation theorem. For sake of simplicity, we conduct the proof in the case $\overline{S P S}_{1}$ is pure PAYG, that is $\bar{F}_{1}(t)=0 \quad \forall t \in T$.

We begin with proving [T1]. By [A2], the instantaneous rate of return on the $A P S_{2}$ pension liability is recognised according to rule (7). We note that 
$\forall t \geq t_{i}$ it is

$$
r-r_{L}(t)=\left(1-D_{c}(t)\right)\left(r-\bar{\sigma}_{1}\right) .
$$

By [A1], the quantity at right side of (8) is not negative. Therefore, it is $r \geq r_{L}(t)$ and, consequently, $F_{2}(t)\left(r-r_{L}(t)\right) \geq 0$, too.

By [A3], starting from $t_{i}$, the no negative compensation flow is instantly transferred from $A P S_{2}$ to $P P S_{1}$ and the evolution equations of the two funds result in

$$
\begin{aligned}
& \dot{F}_{1}(t)=F_{1}(t) r+C_{1}(t)-P_{1}(t)+F_{2}(t)\left(r-r_{L}(t)\right) \\
& \dot{F}_{2}(t)=F_{2}(t) r+C_{2}(t)-P_{2}(t)-F_{2}(t)\left(r-r_{L}(t)\right) .
\end{aligned}
$$

The two funds, $F_{1}(t)$ and $F_{2}(t)$, following modified equations (9) and 10 respectively, are referred to as the "compensated funds".

From 10p, it can be seen that the rate of return actually recognised on the $A P S_{2}$ fund is equal to $r_{L}(t)$, which is the rate of return on the pension liability. In this way, $A P S_{2}$ proves to be fully-funded, that is $F_{2}(t)=L_{2}^{T}(t) \forall t \geq t_{i}$.

We prove [T2]. For each $t \geq t_{i}$, relatively to $P P S_{1}$, we consider the time derivative of the level of the unfunded pension liability in relation to wages, given by

$$
\dot{\beta}_{1}(t)=\frac{1}{W_{1}(t)}\left(\dot{L}_{1}^{T}(t)-\dot{F}_{1}(t)-\left(L_{1}^{T}(t)-F_{1}(t)\right) \frac{\dot{W}_{1}(t)}{W_{1}(t)}\right),
$$

where $\frac{\dot{W}_{1}(t)}{W_{1}(t)}$ is the instantaneous wage growth rate, which is equal to $\bar{\sigma}_{1}$.

Since the derivative of the pension liability follows equation (4) and the derivative of the fund follows equation (9), after substituting them in (11), we obtain

$$
\begin{aligned}
\dot{\beta}_{1}(t) & =\frac{1}{W_{1}(t)}\left(L_{1}^{T}(t) r_{L}(t)-F_{1}(t) r-F_{2}(t)\left(r-r_{L}(t)\right)-L_{1}^{T}(t) \bar{\sigma}_{1}+F_{1}(t) \bar{\sigma}_{1}\right) \\
& =\frac{1}{W_{1}(t)}\left(L_{1}^{T}(t)\left(r_{L}(t)-\bar{\sigma}_{1}\right)-F_{1}(t)\left(r-\bar{\sigma}_{1}\right)-F_{2}(t)\left(r-r_{L}(t)\right)\right) .
\end{aligned}
$$

By means of rule (7), we have

$$
r_{L}(t)-\bar{\sigma}_{1}=D_{c}(t)\left(r-\bar{\sigma}_{1}\right) .
$$

Taking into account (8) and $(13)$, from $(12)$ it follows

$$
\begin{aligned}
& \dot{\beta}_{1}(t)= \\
& =\frac{1}{W_{1}(t)}\left(L_{1}^{T}(t) D_{c}(t)\left(r-\bar{\sigma}_{1}\right)-F_{1}(t)\left(r-\bar{\sigma}_{1}\right)-F_{2}(t)\left(1-D_{c}(t)\right)\left(r-\bar{\sigma}_{1}\right)\right) \\
& =\frac{1}{W_{1}(t)}\left(r-\bar{\sigma}_{1}\right)\left(L_{1}^{T}(t) D_{c}(t)-F_{1}(t)-F_{2}(t)+F_{2}(t) D_{c}(t)\right) \\
& =\frac{1}{W_{1}(t)}\left(r-\bar{\sigma}_{1}\right)\left(D_{c}(t)\left(L_{1}^{T}(t)+F_{2}(t)\right)-F_{1}(t)-F_{2}(t)\right) \text {. }
\end{aligned}
$$


As $A P S_{2}$ is fully-funded, we have $F_{2}(t)=L_{2}^{T}(t) \quad \forall t>t_{i}$, and we obtain $\dot{\beta}_{1}(t)=0 \quad \forall t \geq t_{i}$ as the quantity at the right side of $\sqrt{14}$ is identically null. Therefore, it is $\beta_{1}(t)=\bar{\beta}_{1}\left(t_{i}\right)=\bar{\beta}_{1}$.

We prove [T3]. We recall that $\overline{S P S}_{1}$ is a pure PAYG system in a state of stable sustainability and, therefore, it is

$$
\bar{\beta}_{1}(t)=\frac{\bar{L}_{1}^{T}(t)}{\bar{W}_{1}(t)}=\bar{\beta}_{1}
$$

As previously demonstrated in [T2], relatively to $P P S_{1}$ it also results $\beta_{1}(t)=\bar{\beta}_{1}$. Therefore, it results $\beta_{1}(t)=\bar{\beta}_{1}(t)$, and hence $\frac{L_{1}^{T}(t)-F_{1}(t)}{W_{1}(t)}=\frac{\bar{L}_{1}^{T}(t)}{\bar{W}_{1}(t)} \quad \forall t \geq t_{i}$. Since $W_{1}(t)=\bar{W}_{1}(t)$, it follows that

$$
L_{1}^{T}(t)-\bar{L}_{1}^{T}(t)=F_{1}(t) \quad \forall t \geq t_{i}
$$

It should be noted that starting from the entry of the demographic wave the $P P S_{1}$ pension liability cannot be less than the $\overline{S P S}_{1}$ pension liability. In fact, at each time the pension liability of each $P P S_{1}$ participant profits by a rate of return, $r_{L}(t)$, which is not less than the rate of return that would have had in $\overline{S P S}_{1}$, namely $\bar{\sigma}_{1}$. The additional return is covered by the no negative compensation transfer. Hence, at an aggregate level, we have

$$
L_{1}^{T}(t)-\bar{L}_{1}^{T}(t) \geq 0 \quad \forall t \geq t_{i}
$$

and hence, by the comparison between $(16)$ and $(17)$, it follows that $F_{1}(t) \geq 0 \quad \forall t \geq t_{i}$, namely $P P S_{1}$ is sustainable in $T$.

REMARK 2 From the proof, it is also easy to see that the pension benefit of each $P P S_{1}$ participant is constituted by two components. The first one is equal to the pension benefit that each participant would have had in the pre-existing stable system, namely in $\overline{S P S}_{1}$, and it is covered by the current contributions. The second one is the no negative additional component, which is financed by the compensation transfer and is fully-funded.

REMARK 3 Under the assumption that we will indicate in the following, $P P S_{1}$ "comes back" to old $\overline{S P S}_{1}$, that would be remained in a state of ideal general stability without the wave effect.

When the demographic wave exhausts, namely when $A P S_{2}$ de facto has no participants, then fund $F_{2}(t)$ falls to zero and the compensation transfer from $A P S_{2}$ to $P P S_{1}$ vanishes (approaches to zero in exponential way). Relatively to $P P S_{1}, F_{1}(t)$ is no more fed by the compensation transfer, while the current contributions are used to pay for the pension benefit that each participant would have had in the pre-existing stable system, namely in $\overline{S P S}_{1}$. De facto, $F_{1}(t)$ remains subjected only to the following two effects: it increases due to the rate of interest, $r$; it decreases since it is used to pay for the no negative additional part of the current expenditure. 
We consider indicator $\tilde{\gamma}_{1}(t) \tilde{\nu}_{1}(t)$ that is defined as the indicator that satisfies the following equality

$$
\frac{L_{1}^{T}(t)}{\gamma_{1}(t) \nu_{1}(t)}=\frac{\bar{L}_{1}^{T}(t)}{\bar{\gamma}_{1}(t) \bar{\nu}_{1}(t)}+\frac{F_{1}(t)}{\tilde{\gamma}_{1}(t) \tilde{\nu}_{1}(t)},
$$

namely it is the divisor of the fund in pension expenditure such that the PPS pension expenditure is equal to the $\overline{S P S}_{1}$ pension expenditure plus the additional component covered by the fund (the second term at r.h. side).

If it is assumed that $r-\frac{1}{\tilde{\gamma}_{1}(t) \tilde{\nu}_{1}(t)}<\bar{\sigma}_{1} \quad \forall t \geq t_{i}$, then it is $\lim _{t \rightarrow \infty} \frac{F_{1}(t)}{W_{1}(t)}=0$. Consequently, $\lim _{t \rightarrow \infty} \frac{L_{1}^{T}(t)}{W_{1}(t)}$ exists and it is $\lim _{t \rightarrow \infty} \frac{L_{1}^{T}(t)}{W_{1}(t)}=\lim _{t \rightarrow \infty} \frac{\bar{L}_{1}^{T}(t)}{\bar{W}_{1}(t)}=\bar{\beta}_{1}$, namely $P P S_{1}$ "comes back" to $\overline{S P S}_{1}$.

\section{References}

[1] M. ANGRISANI. Funded and unfunded systems: two ends of the same stick. 28th International Congress of Actuaries PARIS: ICA, 2006.

[2] M. ANGRISANI. The logical sustainability of the pension system. Pure Mathemathics and Applications, 19:67-81, 2008.

[3] M. ANGRISANI, A. ATTIAS, S. BIANCHI, and Z. VARGA. Sustainability of a pay-as-you-go pension system by dynamic immigration control. Applied Mathematics and Computation, 219(5):2442-2452, 2012.

[4] M. ANGRISANI and C. DI PALO. An extension of aaron's sustainable rate of return to partially funded pension systems. International Journal of Sustainable Economy, 4(3):213-233, 2012.

[5] N. S. BLOMQUIST and H. WIJKANDER. Fertility waves, aggregate savings and the rate of interest. Journal of Population Economics, 7(1):27-48, 1994.

[6] G. BONOLI and T. SHINKAWA. Population ageing and the logics of pension reform in Western Europe, East Asia and North America. Ageing and pension reform around the world: evidence from eleven countries, pages $1-23,2005$.

[7] M. FELDSTEIN and E. RANGUELOVA. Accumulated pension collars: A market approach to reducing the risk of investment-based social security reform. Technical report, National Bureau of Economic Research, 2000.

[8] R. HOLZMANN, E. PALMER, and D. ROBALINO. Nonfinancial Defined Contribution Pension Schemes in a Changing Pension World: Volume 1 Progress, issues, and implementation, volume 1. World Bank Publications, 2012. 
[9] R. HOLZMANN, E. PALMER, and D. ROBALINO. Nonfinancial Defined Contribution Pension Schemes in a Changing Pension World: Volume 2 Gender, Politics, and Financial Stability, volume 2. World Bank Publications, 2012.

[10] Human Mortality Database. Data on mortality. Book, University of California, Berkeley (USA) and Max Planck Institute for Demographic Research (Germany). Available at www.humanmortality.de, (data downloaded 2012).

[11] M. KNELL. Pay-As-You-Go A Relict from the Past or a Promise for the Future. Winning contribution of the Hannes Androsch Prize, 2011.

[12] R. LEE. The demographic transition: Three centuries of fundamental change. Journal of Economic Perspectives, 17(4):167-190, 2003.

[13] F. MODIGLIANI, M. CEPRINI, and L. MURALIDHAR. An MIT Solution to the Problems of Social Security Crisis. Technical report, MIT Sloan Working Paper SWP4051, 1999.

[14] A. PIANESE, A. ATTIAS, and Z. VARGA. Dynamic immigration control improving inverse old-age dependency ratio in a pay-as-you-go pension system. Decision Support Systems, 64:109-117, 2014.

[15] National Social Insurance Board (RFV). The Swedish Pension System Annual Report 2001. Report, National Social Insurance Board, 2002. 